\title{
Achromobacter xylosoxidans: An Emerging Pathogen Carrying Different Elements Involved in Horizontal Genetic Transfer
}

\author{
German Matías Traglia • Marisa Almuzara • Andrea Karina Merkier • \\ Christina Adams • Laura Galanternik • Carlos Vay • \\ Daniela Centrón · María Soledad Ramírez
}

Received: 21 January 2012/Accepted: 16 August 2012/Published online: 28 August 2012

(C) The Author(s) 2012. This article is published with open access at Springerlink.com

\begin{abstract}
In the last few years, numerous cases of multidrug-resistant Achromobacter xylosoxidans infections have been documented in immunocompromised and cystic fibrosis patients. To gain insights into the molecular mechanisms and mobile elements related to multidrug resistance in this bacterium, we studied 24 non-epidemiological A. xylosoxidans clinical isolates from Argentina. Specific primers for plasmids, transposons, insertion sequences, bla $a_{\mathrm{ampC}}$, intII, and intI2 genes were used in PCR reactions. The obtained results showed the presence of wide host range IncP plasmids in ten isolates and a high dispersion of class 1 integrons $(n=10)$ and class 2 integrons $(n=3)$. Four arrays in the variable region (vr) of class 1 integrons were identified carrying different gene cassettes as the aminoglycoside resistance $a a c\left(6^{\prime}\right)-I b$ and $a a d A 1$, the trimethoprim resistance
\end{abstract}

Electronic supplementary material The online version of this article (doi:10.1007/s00284-012-0213-5) contains supplementary material, which is available to authorized users.

G. M. Traglia · A. K. Merkier · C. Adams · D. Centrón ·

M. S. Ramírez (凶)

Laboratorio de Investigaciones de los Mecanismos de Resistencia a Antibióticos, Instituto de Microbiología y Parasitología Médica (IMPaM, UBA-CONICET), Facultad de Medicina, Universidad de Buenos Aires, CONICET, Paraguay 2155 Piso 12, 1121 Buenos Aires, Argentina e-mail: ramirez.mariasoledad@gmail.com

M. Almuzara · C. Vay

Laboratorio de Bacteriología Clínica, Departamento de Bioquímica Clínica, Instituto de Fisiopatología y Bioquímica Clínica, Hospital de Clínicas José de San Martín, Facultad de Farmacia y Bioquímica, Universidad de Buenos Aires,

Buenos Aires, Argentina

L. Galanternik

Hospital de Niños Ricardo Gutiérrez, Buenos Aires, Argentina $d f r A l$ and $d f r A 16$, and the $\beta$-lactamase $b l a_{\text {OXA-2. In only one }}$ of the class 2 integrons, a vr was amplified that includes sat2-aadA1. The bla $a_{\mathrm{ampC}}$ gene was found in all isolates, confirming its ubiquitous nature. Our results show that A. xylosoxidans clinical isolates contain a rich variety of genetic elements commonly associated with resistance genes and their dissemination. This supports the hypothesis that A. xylosoxidans is becoming a reservoir of horizontal genetic transfer elements commonly involved in spreading antibiotic resistance.

\section{Introduction}

Achromobacter spp. is a rarely nosocomial and community pathogen, being Achromobacter xylosoxidans the most frequent species among Achromobacter spp. isolates [6, 8, 18]. Many reports of $A$. xylosoxidans infections are documented in immunocompromised and cystic fibrosis (CF) patients, where its pathogenic role has not yet been properly clarified [7, 8]. In Argentina, the relative frequency of A. xylosoxidans among the uncommon non-glucose-fermenting gram-negative bacilli infections has been increasing reaching $66 \%$ of total non-glucose-fermenting gram-negative bacilli infection isolates [18].

Although clinical A. xylosoxidans isolates usually show multiple drug resistance, the relative low attention paid to this pathogen resulted in poor understanding of their resistance mechanisms. Little is known about molecular mechanisms and transferable elements contributing to the acquisition and dissemination of antibiotic resistance determinants in A. xylosoxidans clinical isolates.

The aim of this study was to explore the occurrence of mobile elements related to antibiotic-resistance determinants among a collection of 24 non-epidemiological-related 
Table 1 Characteristic and obtained results of the 24 A. xylosoxidans isolates used in the study

\begin{tabular}{|c|c|c|c|c|c|c|c|c|c|}
\hline Isolate $^{\mathrm{a}}$ & Hospital & Year & Source $^{b}$ & IncP & IS26 & IS440 & intII & $\mathrm{vr}^{\mathrm{c}}$ & $\overline{i n t 12}$ \\
\hline Ax79 & Center 2 & 2004 & $\mathrm{NP}$ & + & - & + & + & $d f r A 1-a a d A 1$ & + \\
\hline Ax169 & Center 3 & 2004 & $\mathrm{NP}$ & + & - & + & + & $d f r A 1-a a d A 1$ & + \\
\hline Ax126 & Center 1 & 2001 & $\mathrm{NP}$ & + & + & - & + & $d f r A 1-a a d A 1$ & + \\
\hline Ax144 & Center 1 & 2001 & $\mathrm{NP}$ & + & - & + & - & NA & - \\
\hline Ax69 & Center 2 & 2002 & $\mathrm{CF}$ & - & - & + & - & NA & - \\
\hline Ax72 & Center 2 & 2007 & $\mathrm{CF}$ & + & - & - & + & $a a c\left(6^{\prime}\right)-I b$ & - \\
\hline Ax77 & Center 2 & 2007 & $\mathrm{CF}$ & - & - & + & - & NA & - \\
\hline $\mathrm{Ax} 210$ & Center 3 & 2007 & $\mathrm{CF}$ & - & - & - & - & NA & - \\
\hline Ax81 & Center 2 & 2008 & $\mathrm{CF}$ & - & - & - & - & NA & - \\
\hline Ax82 & Center 2 & 2008 & $\mathrm{CF}$ & - & - & - & - & NA & - \\
\hline $\mathrm{Ax} 90$ & Center 2 & 2008 & $\mathrm{CF}$ & - & - & - & - & NA & - \\
\hline Ax91 & Center 2 & 2008 & $\mathrm{CF}$ & - & - & - & - & NA & - \\
\hline $\mathrm{Ax} 92$ & Center 2 & 2008 & $\mathrm{CF}$ & - & - & - & - & NA & - \\
\hline Ax93 & Center 2 & 2008 & $\mathrm{CF}$ & - & + & - & - & NA & - \\
\hline Ax97 & Center 2 & 2007 & $\mathrm{CF}$ & - & - & - & - & NA & - \\
\hline Ax336 & Center 2 & 2010 & $\mathrm{CF}$ & - & - & + & - & NA & - \\
\hline Ax11 & Center 2 & 2004 & NP & - & - & - & + & $a a c\left(6^{\prime}\right)-I b$ & - \\
\hline Ax 22 & Center 1 & 1995 & NP & - & - & - & - & NA & - \\
\hline $\mathrm{Ax} 44$ & Center 1 & 2006 & NP & + & - & - & + & $d f r A 16$ & - \\
\hline Ax56 & Center 1 & 2003 & NP & + & - & - & + & $a a c\left(6^{\prime}\right)-I b$ & - \\
\hline Ax68 & Center 6 & 2010 & NP & + & - & - & - & NA & - \\
\hline Ax114 & Center 1 & 2002 & NP & + & - & - & + & $d f r A 1-a a d A 1$ & - \\
\hline Ax247 & Center 1 & 2006 & NP & - & - & + & - & NA & - \\
\hline Ax304 & Center 4 & 1996 & NP & - & - & - & + & $b l a_{\mathrm{OXA}-2}$ & - \\
\hline $\mathrm{Ax} 2700$ & Center 5 & 2006 & $\mathrm{NP}$ & + & - & - & - & NA & - \\
\hline
\end{tabular}

NA not applicable

a Isolates of the study: Ax for Achromobacter xylosoxidans

b NP for nosocomial patient's samples and CF for cystic fibrosis patient's samples

${ }^{\mathrm{c}}$ vr: class 1 integron variable region

clinical isolates of A. xylosoxidans recovered in Argentina from six centers.

\section{Materials and Methods}

\section{Bacterial Strains}

Twenty-four non-epidemiological-related clinical isolates of A. xylosoxidans recovered in Argentina from six centers were used (Table 1). All isolates were identified using standard biochemical tests and API 20NE (Biomeriux), and the species level was confirmed by sequencing the $16 \mathrm{~S}$ rRNA gene [19]. Clonal relationships analysis, using the macrorestriction technique, showed the presence of 15 different clones among the isolates included in the study (data not shown). The antibiotic susceptibility was performed by agar dilution method following the general recommendations of the Clinical and Laboratory Standards Institute (CLSI) [4].

\section{DNA Techniques}

Total DNAs were prepared and used as template for PCR reactions. PCR reactions were carried out using the GoTaq enzyme according to manufacturer's instructions (Promega, Madison, WI), and the products were detected by agarose gel electrophoresis. To reveal the presence of transferable determinants associated to horizontal gene transfer, specific primers for plasmids (IncP, IncW, IncA/ C, IncN, IncFII, repAcil), transposons (Tn1331, Tn3, Tn7), insertion sequences (IS) (IS26, IS440), and the $b l a_{\mathrm{ampC}}$, intI1, and intI 2 genes were used (Table 2). The selection of the mobile elements was based on its association with antibiotic-resistance determinants and also its distribution in our hospitals $[12,13,16]$. 
Table 2 Oligonucleotides used in the study

\begin{tabular}{|c|c|c|c|}
\hline Target & Oligonucleotide & Sequence $5^{\prime}-3^{\prime}$ & References \\
\hline \multirow[t]{2}{*}{$\operatorname{IncW}$} & TrwAB1 & AGCGTATGAAGCCCGTGAAGGG & {$[3]$} \\
\hline & TrwAB2 & AAAGATAAGCGGCAGGACAATAACG & {$[3]$} \\
\hline \multirow[t]{2}{*}{$\operatorname{IncP}$} & TrfA2 1 & CGAAATTCATATGGGAGAAGTA & {$[3]$} \\
\hline & TrfA2 2 & CGTTTGCAATGCACCAGGTC & {$[3]$} \\
\hline \multirow[t]{2}{*}{$\operatorname{IncN}$} & KikA1 & ACTTACCTTTATCAACATTCTGGCG & {$[3]$} \\
\hline & KikA2 & CGACTGGTTACTTCCACCTTCGC & {$[3]$} \\
\hline \multirow[t]{2}{*}{$\operatorname{IncF}$} & REPA & GGAGCGATTTGCATTCCG & {$[3]$} \\
\hline & REPC & AAATGAGCCTGTTTGAG & {$[3]$} \\
\hline \multirow[t]{2}{*}{$\operatorname{IncA} / C$} & CA1 & ATGTCGCAGACAGAAAATGC & {$[3]$} \\
\hline & OR1 & CCTTGCAGTTTAATGTGAATAA & {$[3]$} \\
\hline \multirow[t]{2}{*}{ IS26 } & IS26F & GCTGGCTGAACGCGGAG & [9] \\
\hline & IS26R & ATACCTTTGATGGTGGC & [9] \\
\hline \multirow[t]{2}{*}{ IS440 } & IS440F & CTCACTGTTCGCGACT & [9] \\
\hline & IS440R & GGCATGCGCAGTGAGCGG & [9] \\
\hline \multirow[t]{2}{*}{ Tn1331 } & Tn1331NF & GAATTGCCTCGTGATACGCCTATTT & {$[15]$} \\
\hline & Tn1331NR & GCGGCCGCGATAGTTTGGCTGTGAGC AATT & {$[15]$} \\
\hline \multirow[t]{2}{*}{$\operatorname{Tn} 3$} & $\operatorname{Tn} 3 \mathrm{~F}$ & AAGTTCATCGGGTTCGC & [9] \\
\hline & $201 \mathrm{~L}$ & ACTACGATACGGGAGGGCT & [9] \\
\hline \multirow[t]{2}{*}{$\operatorname{tns} A$} & TnsAF & CTCCATATTCACTACTTGGCT & {$[5,14]$} \\
\hline & TnsAR & GCTAACAGTACAAGAAGTTCC & {$[5,14]$} \\
\hline \multirow[t]{2}{*}{$\operatorname{tns} B$} & TnsBF & CATGTGGTCCAAGAACATAAG & {$[5,14]$} \\
\hline & TnsBR & GAGCAAGCATTTACAAAAGC & {$[5,14]$} \\
\hline \multirow[t]{2}{*}{$\operatorname{tns} C$} & TnsCF & GTTTATCGTGATACGGGGG & {$[5,14]$} \\
\hline & TnsCR & GCTATCCCAGTCGCTGGG & {$[5,14]$} \\
\hline \multirow[t]{2}{*}{$\operatorname{tns} D$} & TnsDF & GGGATTGTTAGTCCTAAGC & {$[5,14]$} \\
\hline & TnsDR & CCGTCTAATTTGATAATCTTC & {$[5,14]$} \\
\hline \multirow[t]{2}{*}{ tnsE } & TnsEF & TTGCTCTCTAACCACTCT & {$[5,14]$} \\
\hline & TnsER & TCGATTTGCTGCTTTTGATG & {$[5,14]$} \\
\hline \multirow[t]{2}{*}{$a a c\left(6^{\prime}\right)-I b$} & $\mathrm{aac}(6){ }^{\prime} \mathrm{ibF}$ & TGTGACGGAATCGTTGC & [13] \\
\hline & aac(6)' IbR & CAGTGACGGTTATTCCGC & [13] \\
\hline \multirow[t]{2}{*}{ intI1 } & Inti1F & CGAGGCATAGACTGTAC & {$[12]$} \\
\hline & Inti1R & TTCGAATGTCGTAACCGC & {$[12]$} \\
\hline \multirow[t]{2}{*}{ intI2 } & Inti2F & GCAAATGAAGTGCAACGC & {$[12]$} \\
\hline & Inti2R & ACACGCTTGCTAACGATG & {$[12]$} \\
\hline $5^{\prime} C S$ & Sulpro & GCCTGACGATGCGTGGA & {$[12]$} \\
\hline $3^{\prime} C S$ & $3^{\prime} \mathrm{CS}$ & AAGCAGACTTGACCTGATAG & {$[12]$} \\
\hline \multirow[t]{2}{*}{ sat } & SatF & TGAGCAGGTGGCGGAAAC & {$[12]$} \\
\hline & SatR & TCATCCTGTGCTCCCGAG & {$[12]$} \\
\hline \multirow[t]{2}{*}{ aadA1 } & aadA1r & TCATTGCGCTGCCATTC & {$[12]$} \\
\hline & aadA1 & TCGATGACGCCAACTAC & {$[12]$} \\
\hline \multirow[t]{2}{*}{$d f r A l$} & Dhfr1r & CCTGAAATCCCCAGCAA & {$[12]$} \\
\hline & dhfrA1 & AGCTGTTCACCTTTGGC & {$[12]$} \\
\hline \multirow[t]{2}{*}{ bla $_{O X A-2}$} & $\mathrm{Oxa} 2 \mathrm{~F}$ & GAAGAAACGCTACTCGC & {$[12]$} \\
\hline & Oxa2R & TACCCACCAACCCATAC & {$[12]$} \\
\hline \multirow[t]{2}{*}{ dfrA16 } & Dhfr16F & CAAAGGCGAGCAACTTC & This study \\
\hline & Dhfr16R & CACCCTCATCATTCGTA & This study \\
\hline
\end{tabular}




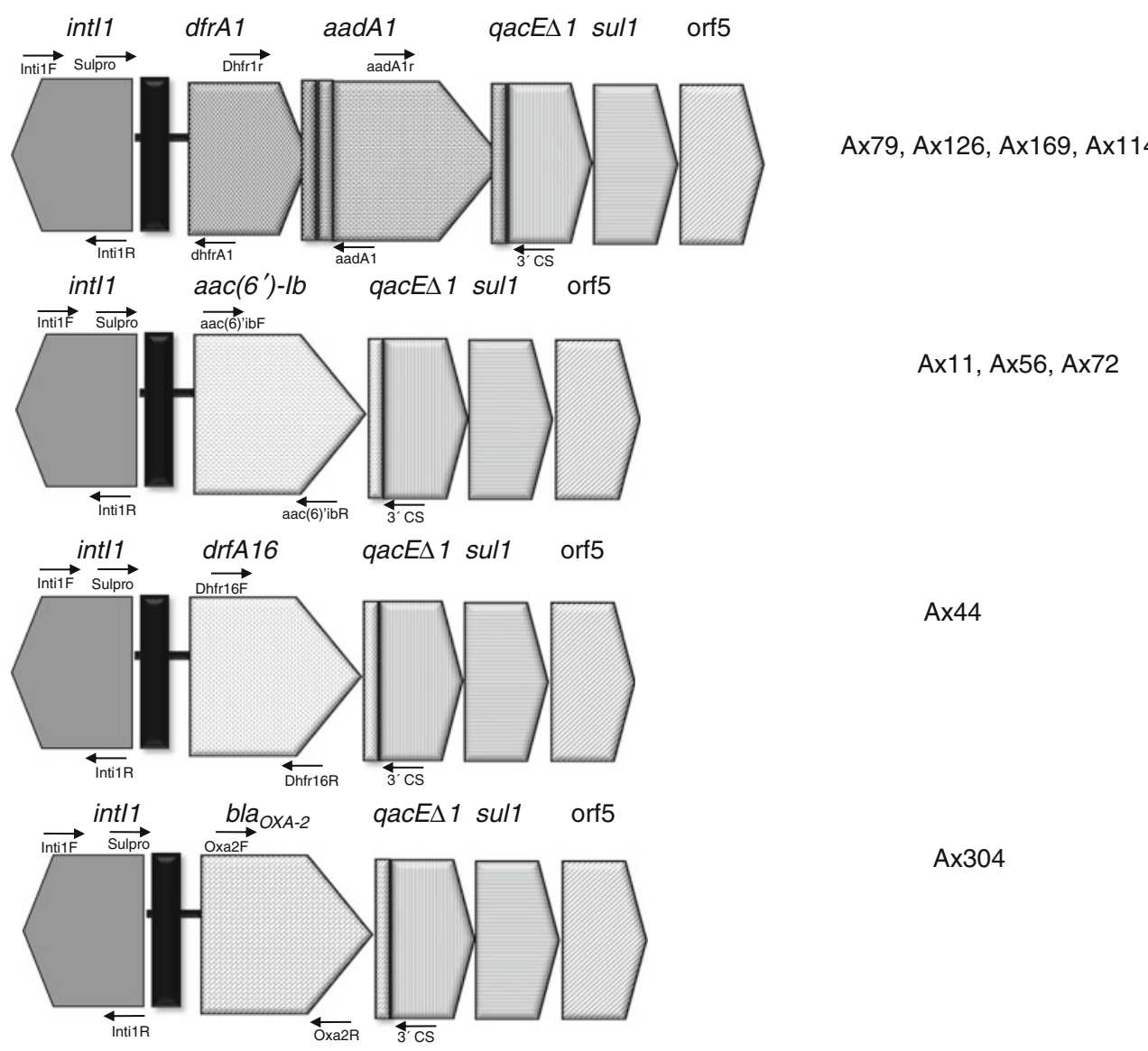

Fig. 1 Schematic representation of arrays of class 1 integrons found among the A. xylosoxidans $(n=24)$ isolates. Thin black vertical closed bar The attI1 site, thin gray vertical closed bar the attC sites of

\section{DNA Sequencing}

PCR products were sequenced after purifying the DNA by using the Wizard SV Gel and PCR clean-up System kit according to the manufacturer's directions (Promega, USA). Sequencing was performed on both DNA strands, using an ABIPrism 3100 BioAnalyzer equipment. The nucleotide sequences were analyzed using the Blast V2.0 software (http://www.ncbi.nlm.nih.gov/BLAST/).

\section{Results and Discussion}

The 24 A. xylosoxidans isolates studied exhibited the typical multiresistance profile previously described for this species, being the third and fourth-generation cephalosporins, fluoroquinolones, and aminoglycosides not active against Achromobacter spp. [18]. All isolates were susceptible to tazobactam, imipenem, and meropenem (Table S1 in Supplementary material).

Among the PCR reactions performed for the selected transferable elements, positive results were obtained in ten the gene cassettes. Arrows The primers used to identify the class 1 integron vr. Figure is not in scale

isolates (42\%) for the IncP plasmids, a wide host range and self-transmissible plasmid important in the dissemination of resistant genes around the world [11] (Table 1). Negative results were obtained for the other Inc groups searched (IncW, IncA/C, IncN, IncFII). Sequence analysis of the amplification products showed $99 \%$ of identity in 200-bp length with the replication gene $\operatorname{trfA}$ (AN GU186864). The $\mathrm{GC} \%$ of the trfA replication gene of IncP plasmid is $60.5 \%$, which is very similar to the GC\% (67\%) of A. xylosoxidans. We also noticed in this study that most isolates containing IncP plasmids corresponded to nosocomial isolates $(n=9)$. In only one $\mathrm{CF}$ patient isolate (Ax72), an IncP plasmid was identified.

Regarding IS and transposons, positive results were obtained for IS26 $(n=2)$ and IS440 $(n=7)$ (Table 1), two ISs frequently associated to antimicrobial resistance genes and to classes 1 and 2 integrons [1,2,10], obtaining negative results for the transposons $\operatorname{Tn} 1331, \operatorname{Tn} 3$, and $\operatorname{Tn} 7$.

In addition, a high dispersion of class 1 integrons was found (42\%). Most of the positive isolates corresponded to nosocomial patient samples $(n=9)$, being only one positive isolate from a CF patient sample (Ax72). To 
Table 3 Minimal inhibitory concentration $(\mu \mathrm{g} / \mathrm{ml})$ of integron positive strains

\begin{tabular}{|c|c|c|c|c|c|c|c|c|c|c|}
\hline Isolate & CAZ & FEP & PIP & IPM & MEM & AMK & GEN & TMP & CIP & $\mathrm{vr}^{\mathrm{a}}$ \\
\hline Ax79 & 8 & 32 & 0.25 & 1 & 0.125 & 128 & 128 & 0.25 & 8 & dfrAl-aadAl \\
\hline Ax169 & 32 & 128 & 0.25 & 0.5 & 0.5 & 128 & 128 & 1 & 16 & dfrAl-aadAl \\
\hline Ax126 & 4 & 32 & 0.5 & 1 & 0.25 & 128 & 128 & 0.125 & 16 & dfrAl-aadA1 \\
\hline Ax72 & 4 & 32 & 0.25 & 1 & 0.25 & 256 & 256 & 4 & 6 & $a a c\left(6^{\prime}\right)-I b$ \\
\hline Ax11 & 32 & 128 & 8 & 4 & 0.24 & 128 & 128 & 64 & 64 & $a a c\left(6^{\prime}\right)-I b$ \\
\hline $\mathrm{Ax} 44$ & 16 & 32 & 0.5 & 1 & 0.5 & 128 & 128 & 256 & 4 & $d f r A 16$ \\
\hline Ax56 & 8 & 32 & 8 & 2 & 0.06 & 64 & 32 & 0.125 & 2 & $a a c\left(6^{\prime}\right)-I b$ \\
\hline Ax114 & 16 & 32 & 0.125 & 1 & 0.125 & 128 & 128 & 0.125 & 16 & $d f r A 1-a a d A 1$ \\
\hline Ax304 & 32 & 128 & 8 & 4 & 0.125 & 128 & 128 & 32 & 4 & $b l a_{\text {OXA-2 }}$ \\
\hline
\end{tabular}

CAZ ceftazidime, FEP cefepime, PIP piperacillin, IPM imipenem, MEM meropenem, AMK amikacin, GEN gentamicin, TMP trimethoprimsulfamethoxazole, $C I P$ ciprofloxacin

a vr: class 1 integron variable region found in the Ax isolates

characterize the vr of class 1 integrons, PCR cartography was carried out as previously described [12]. Four vr were identified, being all the arrays different to the previous arrays reported in this species (Table 1; Fig. 1). Among the gene cassettes identified in the class 1 integron context, aminoglycosides-resistance genes $a a c\left(6^{\prime}\right)-I b$ and $a a d A l$, the trimethoprim-resistance genes $d f r A l$ and $d f r A l 6$, and the $\beta$-lactamase $b l a_{\mathrm{OXA}-2}$ were found. The obtained MICs in the positive integron isolates to several antibiotics are exposed in Table 3. No clear contribution of gene cassettes could be established in the studied isolates. Only in the strain Ax44, harboring the gene cassette $d f r A 16$, a contribution to the MIC to TMS $(256 \mu \mathrm{g} / \mathrm{ml})$ could be suggested, as it corresponded to the highest value among isolates under scrutiny (Table S1 in Supplementary material).

Furthermore, three nosocomial isolates apart from harboring class 1 integrons also have class 2 integrons (Ax79, Ax126, and Ax169) (Table 1). To identify the gene cassette content found in the variable region of class 2 integrons, PCR cartography was performed using different combinations of primers $[5,14,16]$. Only positive amplifications were obtained for the Ax126 showing the presence of the array intI2-sat2-aadA1. The occurrence of the Tn7 transposition gene was also searched, showing that the tns $E$ gene was present in all isolates, being the tns $B$ also present in the Ax126 isolate. The rest of the genes gave negative results. To the best of our knowledge, this is the first description of class 2 integrons in Achromobacter spp. [16]. No association of integrons with IS26 and IS440 was found in this study.

In relation with the $b l a_{\mathrm{ampC}}$ gene previously described in this species [17], it was found in all isolates, confirming its ubiquitous nature.

The exposed results showed that almost all isolates (17/24) included in this study have the capability of carrying ISs, R plasmids, and integrons, associated to horizontal gene transfer usually found in gram-negative clinical isolates. Moreover, the similar GC\% between the trfA replicon of the IncP plasmid and the A. xylosoxidans genome reinforces the argument that $A$. xylosoxidans could be considered as a reservoir of transferable elements. It is likely that its intrinsic antibiotic multidrug resistant profile that ensures its selection under antibiotic pressure, along with its ability to survive in fluids and in the environment [18], makes A. xylosoxidans a reservoir of transferable elements that could contribute to the dissemination and acquisition of antimicrobial resistance mechanisms within the nosocomial environment.

Acknowledgments M.S.R and D.C. are members of the Carrera del Investigador Científico, CONICET, Argentina. This study was supported by Grant UBACyT 20020100300013 from UBA and PIP 11420100100152 from CONICET to M.S.R., UBACyT M008 and B084 Buenos Aires, Argentina to D.C. and C.V., respectively. C.A. was supported by LA Basin Minority Health and Health Disparities International Research Training Program (MHIRT) 5T37MD00136814 (National Institute on Minority Health and Health Disparities).

Open Access This article is distributed under the terms of the Creative Commons Attribution License which permits any use, distribution, and reproduction in any medium, provided the original author(s) and the source are credited.

\section{References}

1. Antunes P, Machado J, Peixe L (2007) Dissemination of sul3containing elements linked to class 1 integrons with an unusual $3^{\prime}$ conserved sequence region among Salmonella isolates. Antimicrob Agents Chemother 51:1545-1548

2. Aubert D, Naas T, Nordmann P (2003) IS1999 increases expression of the extended-spectrum beta-lactamase VEB-1 in Pseudomonas aeruginosa. J Bacteriol 185:5314-5319

3. Carattoli A, Bertini A, Villa L, Falbo V, Hopkins KL, Threlfall EJ (2005) Identification of plasmids by PCR-based replicon typing. J Microbiol Methods 63:219-228 
4. CLSI (2008) Performance standards for antimicrobial susceptibility testing. Clinical and Laboratory Standards Institute, Wayne, PA

5. Flores C, Qadri MI, Lichtenstein C (1990) DNA sequence analysis of five genes; tns $A, B, C, D$ and $E$, required for Tn7 transposition. Nucleic Acids Res 18:901-911

6. Gomez-Cerezo J, Suarez I, Rios JJ, Pena P, Garcia de Miguel MJ, de Jose M, Monteagudo O, Linares P, Barbado-Cano A, Vazquez JJ (2003) Achromobacter xylosoxidans bacteremia: a 10-year analysis of 54 cases. Eur J Clin Microbiol Infect Dis 22:360-363

7. Hansen CR, Pressler T, Nielsen KG, Jensen PO, Bjarnsholt T, Hoiby N (2010) Inflammation in Achromobacter xylosoxidans infected cystic fibrosis patients. J Cyst Fibros 9:51-58

8. Magni A, Trancassini M, Varesi P, Iebba V, Curci A, Pecoraro C, Cimino G, Schippa S, Quattrucci S (2010) Achromobacter xylosoxidans genomic characterization and correlation of randomly amplified polymorphic DNA profiles with relevant clinical features [corrected] of cystic fibrosis patients. J Clin Microbiol 48:1035-1039

9. Merkier AK (2009) Caracterizacion de B-lactamasas en bacilos gram negativos no fermentadores de la glucosa. Thesis Doctoral, Universidad de Buenos Aires

10. Naas T, Poirel L, Karim A, Nordmann P (1999) Molecular characterization of In50, a class 1 integron encoding the gene for the extended-spectrum beta-lactamase VEB-1 in Pseudomonas aeruginosa. FEMS Microbiol Lett 176:411-419

11. Novais A, Canton R, Valverde A, Machado E, Galan JC, Peixe L, Carattoli A, Baquero F, Coque TM (2006) Dissemination and persistence of blaCTX-M-9 are linked to class 1 integrons containing CR1 associated with defective transposon derivatives from Tn 402 located in early antibiotic resistance plasmids of IncHI2, IncP1-alpha, and IncFI groups. Antimicrob Agents Chemother 50:2741-2750
12. Orman BE, Pineiro SA, Arduino S, Galas M, Melano R, Caffer MI, Sordelli DO, Centron D (2002) Evolution of multiresistance in nontyphoid salmonella serovars from 1984 to 1998 in Argentina. Antimicrob Agents Chemother 46:3963-3970

13. Quiroga MP, Andres P, Petroni A, Soler Bistue AJ, Guerriero L, Vargas LJ, Zorreguieta A, Tokumoto M, Quiroga C, Tolmasky ME, Galas M, Centron D (2007) Complex class 1 integrons with diverse variable regions, including $a a c\left(6^{\prime}\right)-I b-c r$, and a novel allele, $q n r B 10$, associated with ISCR1 in clinical enterobacterial isolates from Argentina. Antimicrob Agents Chemother 51:4466-4470

14. Ramirez MS, Quiroga C, Centron D (2005) Novel rearrangement of a class 2 integron in two non-epidemiologically related isolates of Acinetobacter baumannii. Antimicrob Agents Chemother 49:5179-5181

15. Ramirez MS, Parenteau TR, Centron D, Tolmasky ME (2008) Functional characterization of $\mathrm{Tn} 1331$ gene cassettes. J Antimicrob Chemother 62:669-673

16. Ramirez MS, Pineiro S, Centron D (2010) Novel insights about class 2 integrons from experimental and genomic epidemiology. Antimicrob Agents Chemother 54:699-706

17. Shin KS, Han K, Lee J, Hong SB, Son BR, Youn SJ, Kim J, Shin HS (2005) Imipenem-resistant Achromobacter xylosoxidans carrying blaVIM-2-containing class 1 integron. Diagn Microbiol Infect Dis 53:215-220

18. Vay CA, Almuzara MN, Rodriguez CH, Pugliese ML, Lorenzo Barba F, Mattera JC, Famiglietti AM (2005) 'In vitro' activity of different antimicrobial agents on gram-negative nonfermentative bacilli, excluding Pseudomonas aeruginosa and Acinetobacter spp. Rev Argent Microbiol 37:34-45

19. Weisburg WG, Barns SM, Pelletier DA, Lane DJ (1991) 16S ribosomal DNA amplification for phylogenetic study. J Bacteriol 173:697-703 